\title{
Simulating Customer-to-Customer Interaction In a B2B Financial Service Business By Empirical Agent-Based Modeling
}

\author{
Makoto Mizuno \\ Meiji University \\ 1-1 Kanda-Surugadai \\ Chiyoda-ku, Tokyo, Japan \\ TEL: +81-3-3296-4164 \\ makmizuno@gmail.com \\ Yutaro Nemoto \\ Tokyo Metropolitan University \\ 6-6 Asahigaoka \\ Hino-shi, Tokyo, Japan \\ yutaro.nemoto@gmail.com \\ Keisuke Oura \\ Shiga University \\ 1-1-1 Banba \\ Hikone-shi, Shiga, Japan \\ kei-oura@biwako.shiga-u.ac.jp
}

\author{
Keiko Toya \\ Meiji University \\ 1-1 Kanda-Surugadai \\ Chiyoda-ku, Tokyo, Japan \\ i.ktoya@gmail.com
}

Shintaro Tanno

AIST

2-3-26 Aomi

Koto-ku, Tokyo, Japan

mgrpx853@gmail.com

Akira Ishii

Tottori University

4-101 Koyama-cho Minami

Tottori, Japan

ishii@damp.tottori-u.ac.jp

\author{
Kana Ozawa \\ Ryutsu Keizai University \\ 120 Ryugasaki-shi \\ Ibaraki, Japan \\ ozawa-kana@rku.ac.jp
}

Kohei Arai
Gunma University
4-2 Aramaki-machi
Maebashi-shi, Gunma, Japan
k_arai@gunma-u.ac.jp
Takaaki Ohnishi
University of Tokyo
7-3-1 Hongo
Bunkyo-ku, Tokyo, Japan
ohnishi.takaaki@i.u-tokyo.ac.jp

\begin{abstract}
Service research has emphasized triad relationships between a firm, employees and customers. To coordinate these stakeholders effectively, it is highly important to understand what service activities are beneficial to all or some of these stakeholders. Yet, the recent increase in $\mathrm{C} 2 \mathrm{C}$ interaction may make the problem more complex. This study proposes a methodology combining statistical techniques and agent-based modeling, which makes it possible to assess the joint impact of each service value and $\mathrm{C} 2 \mathrm{C}$ interaction on the payoffs.
\end{abstract}

\section{Categories and Subject Descriptors}

J.1 [Administrative Data Processing]: Marketing

\section{General Terms}

Management, Measurement, Performance, Economics

\section{Keywords}

Simulation, Agent-based Modeling, Customer Lifetime Value, Customer Satisfaction, Social Interaction

\section{INTRODUCTION}

Service research has historically emphasized a triad relationship between three stakeholders: a firm, employees, and customers, as illustrated typically in "Service Triangle" [1]. This consensus is evolving to the paradigm that value is co-created through the interaction among stakeholders. Thus, the term "Value Cocreation" becomes more dominant recently, which is extended over services in the narrow definition, covering manufacturing goods, of which stream is named "Service-Dominant Logic" [2].

The stakeholders could be essentially conflicting in interest; however, under some conditions, they might be willing to cooperate in order to increase their own payoffs. The school of "Service Profit Chain" focuses on the case that every stakeholder can be better off [3]. Yet, from our viewpoint, value co-creation is not all-or-nothing but a matter of degree. To evaluate the degree of value co-creation based on each stakeholder's payoff, one of the viable ways is using an overall criterion as a function of stakeholders' payoffs. For instance, the framework of Nash bargaining game is applicable, where the product of each player's payoff can be a criterion to maximize [4].

If the payoff of each stakeholder is quantified, the degree of value co-creation is also quantified. This seems to be accomplished via standard statistical techniques. However, if the effect of customerto-customer $(\mathrm{C} 2 \mathrm{C})$ interaction is considerable, as recent research suggests [5], such techniques may not work well. To account for such interaction, we attempt to combine agent-based modeling as a non-standard complex science technique with standard statistical techniques. That is, we propose a hybrid approach.

In the subsequent section, we describe our methodology: firstly, we construct modules to measure and predict each stakeholder's payoff; secondly, we model $\mathrm{C} 2 \mathrm{C}$ interaction as an agent-based model and combine it with other modules. In section 3, we 
explain, using the data provided for this study, how to estimate parameters of each module and to construct a C2C network. In Section 4, we report procedures and results of the simulation, focusing on the effects of $\mathrm{C} 2 \mathrm{C}$ interaction. Finally, we discuss implications and further development of this study.

\section{MODEL}

\subsection{Basic Modules}

To quantify the payoff that a firm acquires through transactions with each customer, we use Customer Lifetime Value (CLV), which has been accepted broadly for customer relationship management or direct marketing [6]. This is the net present value of a stream of future profits obtained from each customer, which is calculated as follows:

$$
C L V_{i}=\sum_{t=1}^{T} \pi_{i t} /(1+d)^{t-1}
$$

where $\pi_{i t}$ is the profit obtained from customer $i$ at time $t, T$ is the time horizon, and $d$ is the discount rate. The aggregated value of CLV over all customers is termed Customer Equity (CE) [7].

To calculate CLV, we need to predict future profits from each customer as a function of individual service values via a statistical technique. Following a spirit of several previous studies [8][9], we propose the following procedure:

1) Initially, each customer is stochastically assigned to a finite number of profitability segments depending on perceived service values.

2) Transitions of customers between the segments are repeated based on a first-order Markov process given a transition probability matrix.

3) The expected profits are given to customers by segments using a linear time-trend model. By aggregating a series of the profits with a certain discount rate, CLV is calculated.

4) By aggregating CLV over all customers, CE is calculated.

To quantify payoffs for customers and employees, we use Customer Satisfaction (CS) and Employee Satisfaction (ES), respectively, measured via questionnaire surveys. The functional relationship between $\mathrm{CS} / \mathrm{ES}$ and perceived service values are statistically estimated.

\subsection{C2C Interaction}

In general, $\mathrm{C} 2 \mathrm{C}$ interaction is seldom observed directly. In this study, money transfer (i.e., transaction) data between customers is used as a proxy of the degree of interaction. Using this data, we construct a social network of customers with weighted links based on the transaction amount between a pair of customers. Specifically, the $\mathrm{C} 2 \mathrm{C}$ interaction process is modeled as follows:

1) Assume that there exists a time period for $\mathrm{C} 2 \mathrm{C}$ interaction before determining CS, ES and CLV. At each time step in this interaction period, each customer makes a choice of whether to imitate others or not with probability $q$ (imitation probability), being constant over time and across customers.

2) If a consumer decides to imitate others, then he/she chooses a customer linked on the $\mathrm{C} 2 \mathrm{C}$ network with probability:

$$
\operatorname{Pr}\{i \text { imitates } j\}=\frac{\exp \left(\theta_{i} \cdot y_{i j}\right)}{\sum_{j^{\prime} \in N(i)} \exp \left(\theta_{i} \cdot y_{i j^{\prime}}\right)}
$$

where $\theta_{i}$ is a scale parameter defining the randomness of a choice, $y_{i j}$ is the proportion of customer $i$ 's transaction amount with customer $j$ over customer $i$ 's total transaction amount, and $N(i)$ is a set of customers linked to customer $i$ on the network. Parameter $\theta_{i}$ is drawn from a uniform distribution within $\left(\theta_{\min }, \theta_{\max }\right)$ initially by customers. The above function is an application of the multinomial logit model.

3) If customer $i$ already decided imitating $j$, his/her perceived service value is replaced by customer $j$ 's one. We back to the first step and repeat these steps $S$ times.

Thus, imitation among customers connected via a $\mathrm{C} 2 \mathrm{C}$ transaction network is incorporated into the model. This module is built by agent-based modeling whereby customers as agents mutually interact and change their perceptions [10]. Simulated customer perceptions become inputs to the basic modules.

\section{Empirical Analyses}

\subsection{Data}

Most of parameters of the above-mentioned modules, except parameters used in the $\mathrm{C} 2 \mathrm{C}$ interaction module $\left(q, \theta_{\min }, \theta_{\max }\right.$, and $S)$, are statistically estimated based on the following data:

- Customer gross profit record (2011-2013, monthly)

- CS and customers' perceived service values (2013)

- $\quad$ ES and employees' perceived service values (2013)

- $\quad$ Customer-to-customer (C2C) money transfer (2012)

These comprehensive data sets became available thanks to the cooperation of a regional finance service firm in Japan.

\subsection{Estimation of Basic Models}

The surveys conducted in this study measures CS and ES on 7point scales; their histograms show remarkable skewness, suggesting ordinal linear regression should not be applied because of violation of the assumption that an objective variable is normally distributed in the population. Alternatively, we applied an ordered multinomial logit model that allows for an ordinal objective variable [11]. Main predictor variables are items for measuring perceived service values, which are developed in the project containing this study as a part [12]. These items are classified into customer-perceived ones and employee-perceived ones depending on the source of information. Also, they are classified into three categories depending on the properties of values: fundamental function, knowledge, and emotional values.

In our study, customers and employees are matched based on their transactional relations (in this B2B service, each customer is served by only an employee, whereas an employee can serve several customer). This feature makes it possible to include employee-perceived service values into a set of predictor variables for predicting CS and vice versa. In doing so, it is expected to assess, for instance, how employees perceive a service value item is associated with satisfaction of customers whom they have contacted. Adding some control variables, the ordered multinomial logit models were estimated for predicting CS/ES via a maximum likelihood method.

The same procedure was applied to predict the initial profitability segments. Only the customers who appeared in both the customer profit record data and the customer survey were analyzed $(\mathrm{N}=1,354)$. Profitability segments are constructed based on "decile," dividing customers into ten equal-size segments 
according to the order of their profit levels. As mentioned before, to which initial segment a customer is assigned is predicted via an ordered logit model. To take heterogeneity in customers into the account, the models are estimated for each of five groups: decile $1-2,3-4 \ldots 9-10$. Overall, the data of 1,354 customers is analyzed for parameter estimation via a maximum likelihood method.

After that, the transition between ten profitability segments is stochastically predicted via a Markov model, where the transition matrix is estimated using customer profit record from 2011 to 2013. The 2014 data is used for validation of the model. The results of estimated parameters and predictive performance of the above models are available from the author.

\subsection{Construction of C2C Network}

A C2C network is constructed for the customers appearing both in customer surveys and $\mathrm{C} 2 \mathrm{C}$ transaction data. In that network, a pair of customers is linked if there is any money transfer between them regardless of the directions. Also, each link is weighted by the amount of money transferred there. The complimentary cumulative distribution function (CCDF) of each node's total transaction amount with others is depicted in Figure 1. This figure indicates that the transaction amount is highly skew distributed, where a few customers transacting much with others and a number of customers transacting little with others coexist. If the relative intensity of $\mathrm{C} 2 \mathrm{C}$ transaction amount represents interaction with others, targeting a few customers with heavy transaction amount will boost its effectiveness of a marketing campaign.

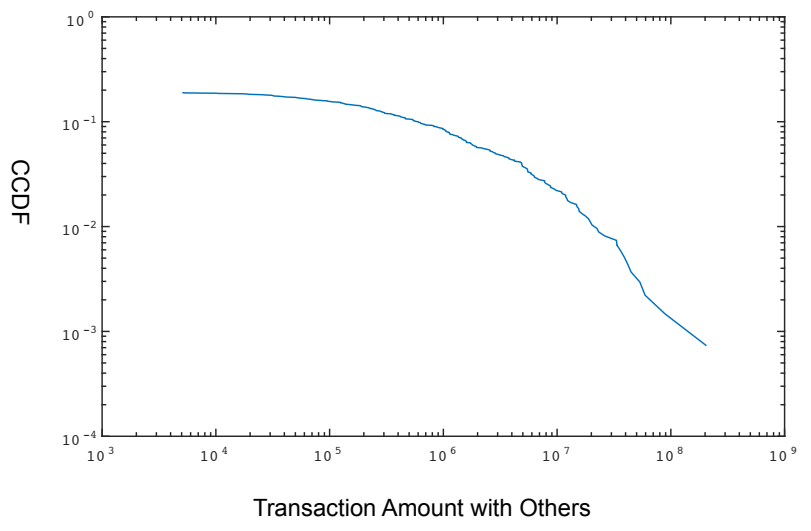

Figure 1. Distribution of Transaction Amount with Others

\section{Simulation \\ 4.1 Contrast Case}

As a reference point to which the effects of contagion of perceptions are compared, we consider the case with no $\mathrm{C} 2 \mathrm{C}$ interaction, where each customer is independently assigned to some profitability segments and moves between segments in a finite time horizon. Because the outcomes of logit models and Markov model are stochastic, we repeat simulation 1,000 times, getting the distributions and the means of predicted values.

To predict CE, CS and ES for each customer in 2013 or later, we used the observations before 2013. The observations in 2014 were not used for estimation, so these can be used for validation of our model. The Spearman's rank correlation coefficient between predicted and observed values is .944 for profitability segment. The Pearson's correlation coefficient between observed/predicted CE (both are logarithmic-transformed) is .864 , excluding cases where $\mathrm{CE}$ is zero or negative. It suggests that our $\mathrm{CE}$ model is validated at the satisfactory level.

\subsection{Interaction Case}

As mentioned in $\mathbf{2 . 2}$, the $\mathrm{C} 2 \mathrm{C}$ interaction process is incorporated into our model as an initial phase before the formation of CLV, $\mathrm{CS}$, and ES. The probability of imitation $(q)$ is chosen at random from $\{0.1,0.3,0.5\}$. The interaction period continues from $s=1$ to 100. At each step, customers decide whether to imitate others or not; in the former case, the customer chooses a customer and imitates him/her with respect to a specific item of customerperceived service values. A parameter defining the randomness of this choice, $\theta_{i}$, is uniformly distributed in $(0,4)$ among customers, varying across customers and over time.

In the illustrative case below, we focus a customer-perceived service value "Prestige" (a customer feels the transaction with a firm is prestigious). The sensitivity analysis in contrast case showed that this service value has the largest impact on $\mathrm{CE}$ without $\mathrm{C} 2 \mathrm{C}$ interaction and the moderate impact on $\mathrm{CS}$. What if $\mathrm{C} 2 \mathrm{C}$ interaction is incorporated her? Figure 2 depicts the average trajectory of the perception "Prestige" diffusing over customers with the repetition of $\mathrm{C} 2 \mathrm{C}$ interaction given a probability of imitation $q$. Findings from this figure are summarized as follows: (1) as interaction is repeated more deeply, the average level of the focus perceived service value increases, while its marginal increment decreases (diminishing return); (2) the higher $q$ (the more likely customers imitate each other), the faster the perception is spread across customers.

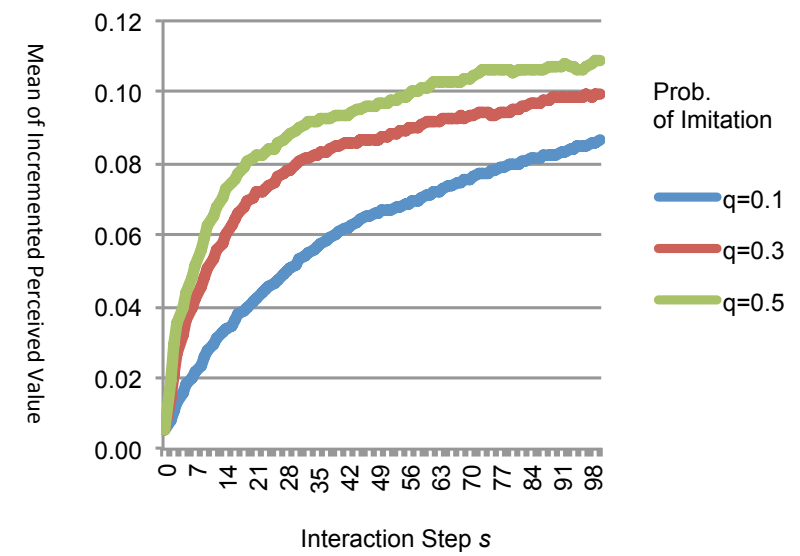

Figure 2. Contagion of Customer-Perceived Value (Value of "Prestige" for Customers)

As Figure 2 shows, the predicted increment of the value varies by not only the probability of imitation $(q)$ but also the depth of interaction steps $(s)$. Accordingly, the average payoffs predicted via simulation should be compared with respect to both $q$ and $s$. Moreover, to quantify the relative impacts of $\mathrm{C} 2 \mathrm{C}$ interaction, we calculate multipliers dividing the means in interaction case by the ones in contrast case. Figure 3 shows the multipliers for CLV, CS, and ES by the depth of interaction steps: $s=10,30$ and 50 and by the probability of imitation: $q=0.1,0.3$ and 0.5 , given $s$. Findings from these are summarized as follows (the detailed results of statistical test are omitted):

1) The impacts of $\mathrm{C} 2 \mathrm{C}$ interaction on $\mathrm{CE}$ could be a nonlinear function of the depth of interaction $(s)$ and the probability of imitation $(q)$. Within a given set of parameters, these impacts are largest when $s=100$ and $q=0.3$ and second largest when $s=100$ and $q=0.1$ or 0.3 . For the extreme case ( $s=100$ and $q=0.5)$, the impact is rather low. 
2) The impacts of $\mathrm{C} 2 \mathrm{C}$ interaction on $\mathrm{CS}$ monotonically increase or at least not decrease with $s$ and $q$. Hence, these are maximal when $s=100$ and $q=0.5$. Their magnitudes are markedly lower than those on $\mathrm{CE}$.

3) The impacts of $\mathrm{C} 2 \mathrm{C}$ interaction on ES are significant except for cases of $s=10$. However, their magnitudes are relatively very low. The parameter of "Prestige" in the ES model is significant, but its magnitude is not so high. As a result, the impact of $\mathrm{C} 2 \mathrm{C}$ interaction on $\mathrm{ES}$ is marginal.
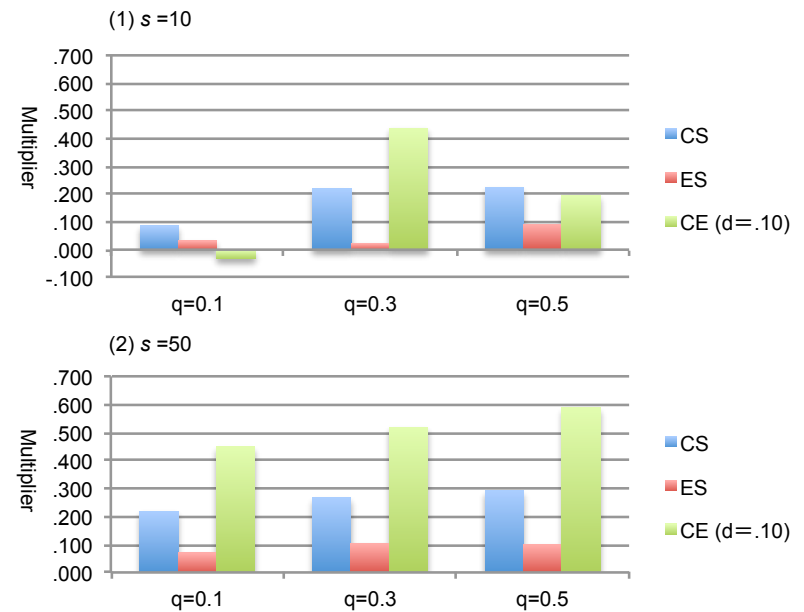

(3) $s=100$

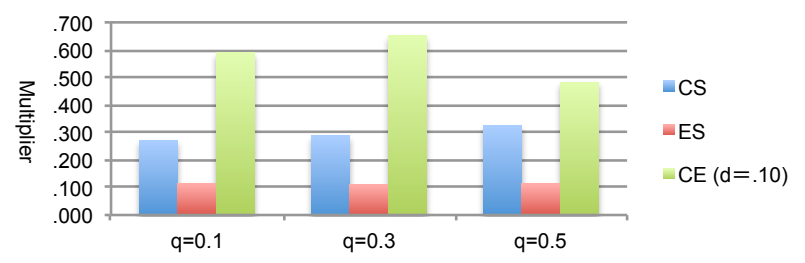

Figure 3. Impact of Customer-Perceived Value on Payoffs (Value of "Prestige" for Customers)

\section{CONCLUDING REMARKS}

Integrating traditional statistical methods with agent-based modeling, we developed a methodology to assess the impact of $\mathrm{C} 2 \mathrm{C}$ interaction on the payoffs for stakeholders (CS for customers, ES for employees and CE for a firm) for a service business. If a service business is seen as a Nash bargaining game between these stakeholders, the equilibrium is obtained by maximizing a product of all stakeholders' payoffs.

Given the data available, we simulated the $\mathrm{C} 2 \mathrm{C}$ interaction process, predict the payoffs and compare those by whether $\mathrm{C} 2 \mathrm{C}$ interaction exists or not. Under the scenario that perceived service value "Prestige" is spread over $\mathrm{C} 2 \mathrm{C}$ network, the average perceived level of this value increases. This incremental effect differs by the probability of imitation or the depth of interaction. This effect seems to be nonlinear, suggesting the existence of equilibrium of Nash bargaining game between stakeholders.

It should be noted that these results depend on the data (particularly, the distribution of service values over all customers, topology of a network connecting them, etc.) and the assumed mechanism of simulation and the scenario of contagion of perceived service values. To generalize our findings, we need to apply this methodology to another organization in the same industry or firms in other industries.

Here we emphasize the possible contributions of the methodology of this study. Traditional statistical modeling, intensively adopted in service research, lacks enough consideration for $\mathrm{C} 2 \mathrm{C}$ interaction. On the other hand, agent-based modeling, developed for handling complex interaction among individual agents, often lacks reliable procedures for empirical validation. Our proposed hybrid methodology would be one of the promising alternatives.

Even methodologically, there are many remaining problems. One of those is to refine statistical techniques so as to infer the causality of perceived service values on payoffs more rigorously. Another is a more sophisticated treatment of social interaction from the limited amount of information.

\section{ACKNOWLEDGMENTS}

We appreciate the financial support of Research Institute of Science and Technology for Society (RISTEX) and the cooperation of an anonymous financial service firm.

\section{REFERENCES}

[1] Binter, M. J. 1995. Building service relationships: it's all about promises. J. of the Academy of Mktg Sci.. 23, 4, 246251.

[2] Vargo, S. L. and Lusch, R. F. 2004. Evolving to a new dominant logic for Marketing. J. of Mktg. 68 (Jan.), 1-17.

[3] Heskett, J. L., Jones, T., Loveman, G. W., Sasser, Jr., W. E., and Schlesinger, L. A. 1994. Putting the service profit chain to work. Harvard Business Review. 72, 2, 164-174.

[4] Aoki, M. 1984. The co-operative game theory of the firm, Oxford University Press, Oxford.

[5] Libai, B., Bolton, R., Bügel, M. S., de Ruyter, K., Götz, O., Risselada, H., and Stephen, A. T. 2010. Customer-tocustomer interactions: broadening the scope of word of mouth. J. of Service Res., 13, 3, 267-282.

[6] Jain, D. and Singh, S. S. 2002. Customer lifetime value in marketing: a review and future directions. J. of Interactive Mktg, 16, 2, 34-46.

[7] Blattberg, R. C., and Deighton, J. 1996. Manage marketing by the customer equity test. Harvard Business Review. (Jul.Aug.) 136-144.

[8] Rust, R. T., Lemon, K. L., and Zeithaml, V. A. 2004. Return on marketing: using customer equity to focus marketing strategy. J. of Mktg. 68(Jan.), 109-127.

[9] Homburg, C., Steiner, V. V., and Totzek, D. 2009. Managing dynamics in a customer portfolio. J. of Mktg, 73(Sep.), 70-89.

[10] Rand, W., and Rust, R. T. 2011. Agent-based modeling in marketing: guidelines for rigor. Int. J. of Res. in Mktg. 28, 3, 181-193.

[11] Franses, P. H., and Paap, R. 2001. Quantitative Models on Marketing Research, Cambridge Univ. Press, Cambridge.

[12] Toya, K. ed. 2015. Developing measurement scales for cocreated values of a firm, employees and customers in a financial service: final report, s RISTEX, in Japanese. 